\title{
APLIKASI INVENTORY TERINTEGRASI ORDER SYSTEM KONSUMEN PADA OTO BENTO PERUMNAS CILEGON MENGGUNAKAN METODE WATERFALL
}

\author{
${ }^{1}$ Riyan Naufal Hay’s, ${ }^{2}$ Ahmad Sugiyarta, ${ }^{3}$ Dessy Eka Winungkas \\ ${ }^{1}$ Prodi Teknik Informatika, ${ }^{2,3}$ Prodi Sistem Informasi \\ Fakultas Teknologi Informasi Universitas Serang Raya \\ Jln.Raya Cilegon Serang Km 5 - Drangong Kota Serang \\ Iriyan.unsera@gmail.com \\ 2amate 4 @gmail.com \\ ${ }^{3}$ dessyeka004@gmail.com
}

\begin{abstract}
Abstrak -Sistem inventory pada Oto Bento Perumnas Cilegon saat ini masih bersifat manual, sehingga dalam proses pengecekan jumlah persediaan bahan baku tidak dapat dilakukan dengan cepat, bahkan sering terjadi kesalahan. Pada proses transaksi order system konsumen dan pembuatan laporan sering terjadi kesalahan karena sistem yang digunakan masih bersifat manual atau belum terkomputerisasi. Maka penulis berharap dengan penelitian ini dapat membangun sebuah aplikasi yang dapat mengatasi permasalahan yang ada. Untuk membangun aplikasi inventory, alat bantu yang digunakan untuk menggambarkan model system adalah berupa diagram UML (Unified Modeling Language), serta menggunakan bahasa pemrograman Vb.Net dan SQL Server sebagai Databasenya. Dan untuk metodologi penelitian yang penulis gunakan adalah menggunakan metode waterfall. Hasil dari penelitian ini adalah sistem inventory dan aplikasi yang telah dirancang dapat membantu dalam proses pengolahan data. Pada sistem informasi yang telah dirancang dapat membantu dalam proses transaksi order system konsumen dan pembuatan laporan agar lebih cepat dan akurat. Aplikasi yang dirancang juga mudah dioperasikan karena menggunakan bahasa dan visual yang mudah dipahami oleh pengguna.
\end{abstract}

Kata Kunci : Aplikasi, Inventory, OrderSystem, Waterfall

\section{Pendahuluan}

Oto Bento merupakan usaha makanan Jepang yang berdiri sejak 9 Desember 1999 dengan sertifikat merk dari departemen hukum dan hak asasi manusia serta telah memiliki lebih dari 100 cabang yang telah tersebar di seluruh Indonesia. Khususnya pada Oto Bento cabang Perumnas Cilegon, kegiatan pengolahan barang di Oto Bento cabang Perumnas Cilegon dari tahun ke tahun terus berlangsung. Pengolahan ini bukan hanya melibatkan barang-barang dan aset lama saja tapi juga barang-barang dan aset baru. Sehingga dengan demikian dari tahun ke tahun jumlah barang ini semakin bertambah. Agar pelaksanaan penyimpanan barang dalam gudang dapat terkelola serta tertata dengan baik, maka perlu dikembangkan suatu aplikasi berupa inventory. Karena apabila dengan cara biasa (proses manual) seperti sekarang, cukup menyulitkan dalam hal pengarsipan penelusuran data barang.

Adapun metode yang digunakan adalah metode air terjun atau yang sering disebut metode waterfall sering dinamakan siklus hidup klasik (classic life cycle), dimana hal ini menggambarkan pendekatan yang sistematis dan juga berurutan pada pengembangan perangkat lunak, dimulai dengan spesifikasi kebutuhan pengguna lalu berlanjut melalui tahapan-tahapan perencanaan (planning), pemodelan (modeling), kontruksi (construction), serta penyerahan sistem ke para pelanggan/pengguna (deployment), yang diakhiri dengan dukungan pada perangkat lunak lengkap yang dihasilkan.

Tujuan dari penelitian ini adalah membuat sebuah aplikasi inventory dimana aplikasi ini akan memudahkan dalam penginputan dan pengecekan persediaan bahan baku, serta diharapkan dapat mengatasi masalah yang ada dan sering terjadi.

\section{Metodologi Penelitian}

Alur dari penelitian ini dapat dilihat pada gambar 1 dibawah ini adapun alur dari peenlitian ini sebagai berikut :

1. Analisis Persyaratan

Seluruh kebutuan software harus bisa didapatkan dalam fase ini, termasuk di dalamnya 
kegunaan software yang diharapkan pengguna dan batasan software. Informasi ini biasanya dapat diperoleh melalui wawancara, survey atau diskusi. Informasi tersebut dianalisis untuk mendapatkan dokumentasi kebutuhan pengguna untuk digunakan pada tahap selanjutnya.

\section{Desain Sistem}

Tahap ini dilakukan sebelum melakukan coding. Tahap ini bertujuan untuk memberikan gambaran apa yang seharusnya dikerjakan dan bagaimana tampilannya. Tahap ini membantu dalam menspesifikasikan kebutuhan hardware dan sistem serta mendefinisikan arsitektur sistem secara keseluruhan.

3. Implementasi

Dalam tahap ini dilakukan pemrograman. Pembuatan software dipecah menjadi modulmodul kecil yang nantinya akan digabungkan dalam tahap berikutnya. Selain itu dalam tahap ini juga dilakukan pemeriksaan terhadap modul yang dibuat, apakah sudah memenuhi fungsi yang diinginkan atau belum.

4. Pengujian Sistem

Di tahap ini dilakukan penggabungan modulmodul yang sudah dibuat dan dilakukan pengujian ini dilakukan untuk mengetahui apakah software yang dibuat telah sesuai dengan desainnya dan masih terdapat kesalahan atau tidak.

5. Pemeliharaan Sistem

Ini merupakan tahap terakhir dalam model waterfall. Software yang sudah jadi dijalankan serta dilakukan pemeliharaan. Pemeliharaan termasuk dalam memperbaiki kesalahan yang tidak ditemukan pada tahap sebelumnya. Perbaikan implementasi unit sistem dan peningkatan jasa sistem sebagai kebutuhan baru.

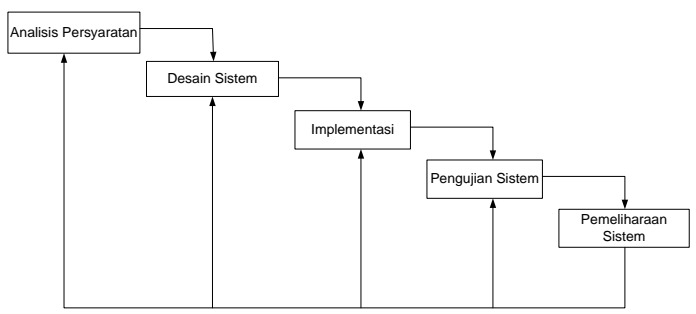

Gambar 1. Bagan Waterfall

\section{A. Analisis Data}

Berdasarkan tujuan dalam penelitian ini maka beberapa analisis yang digunakan dalam penelitian adakah sebagai berikut: Metode air terjun atau yang sering disebut metode waterfall sering dinamakan siklus hidup klasik (classic life cycle), dimana hal ini menggambarkan pendekatan yang sistematis dan juga berurutan pada pengembangan perangkat lunak. (Pressman, 2012)

\section{B. Inventory}

Inventory merupakan sebuah kata yang berasal dari bahasa Inggris Echols dan Shadily merumuskan dalam kamus Besar Bahasa Indonesia sebagai daftar barang disertai dengan nilainya masing-masing yang dimiliki perusahaan dalam kurun waktu tertentu yang digunakan dalam kegiatan usaha perusahaan. Dalam praktek, inventory disebut juga sebagai persediaan barang yang artinya barang-barang biasanya dapat dijumpai digudang tertutup, lapangan, gudang terbuka, atau tempat-tempat penyimpanan lain, baik berupa bahan baku, barang setengah jadi, barang jadi, barang-barang untuk keperluan operasi atau barang-barang untuk keperluan suatu proyek (Indrajit, 2003)

\section{Hasil Dan Pembahasan}

Pada bagian ini dijelaskan secara lengkap tampilan-tampilan layar pada program aplikasi Sistem Inventory.

\section{Form Login}

Form login berfungsi sebagai pengaman dan pintu masuk ke menu utama sistem inventory. Seorang user harus memasukan username dan password dengan benar untuk masuk ke menu utama.

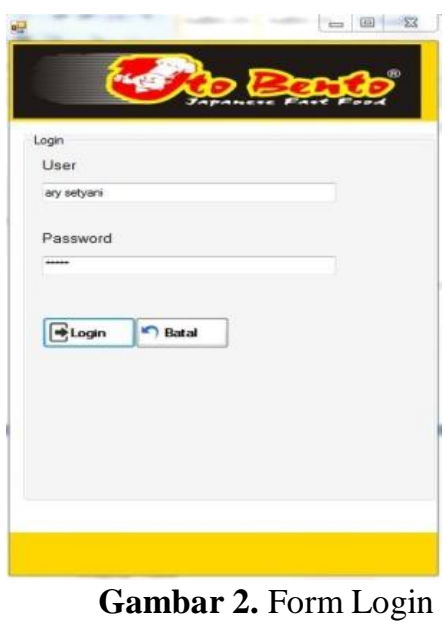

\section{Form Menu Utama}

Form menu utama merupakan pusat dari program aplikasi ini, artinya setiap form dapat dipanggil atau ditampilkan dengan form menu utama ini. 

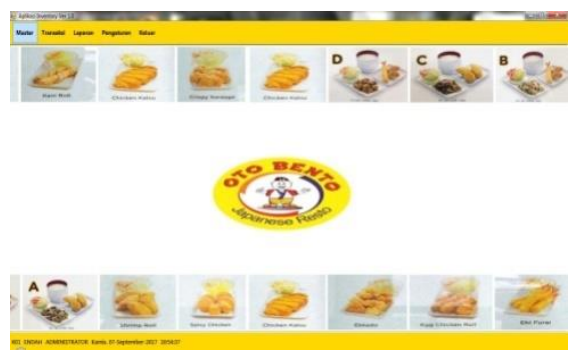

Gambar 3. Form Menu Utama

3. Form Data Produk

Form data produk menampilkan semua data produk dalam satu tabel di form ini yang telah tersimpan dalam database dan untuk menambah atau mengedit data produk.

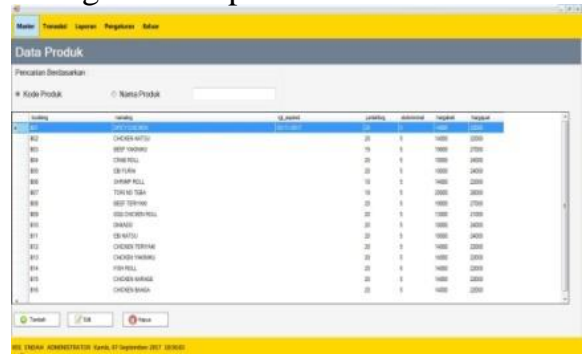

Gambar 4. Form Data Produk

\section{Form Data Supplier}

Form data supplier menampilkan semua data supplier dalam satu tabel di form ini yang telah tersimpan dalam database dan untuk menambah atau mengedit data supplier.

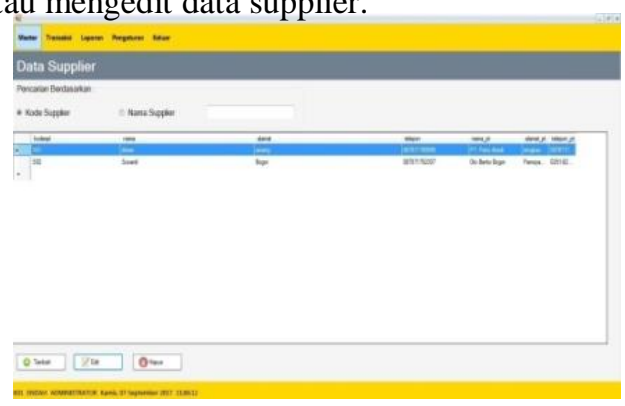

Gambar 5. Form Data Supplier

\section{Form Data Karyawan}

Form data karyawan menampilkan semua data karyawan dalam satu tabel di form ini yang telah tersimpan dalam database dan untuk menambah atau mengedit data karyawan.

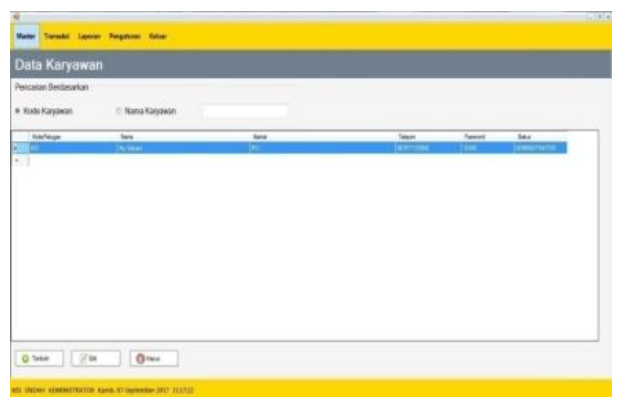

Gambar 6. Form Data Karyawan

6. Form Transaksi Pembelian Produk

Form transaksi pembelian produk menampilkan semua data transaksi pembelian bahan baku dalam satu tabel di form ini yang telah tersimpan dalam database dan untuk memesan dan menyimpan pesanan produk.

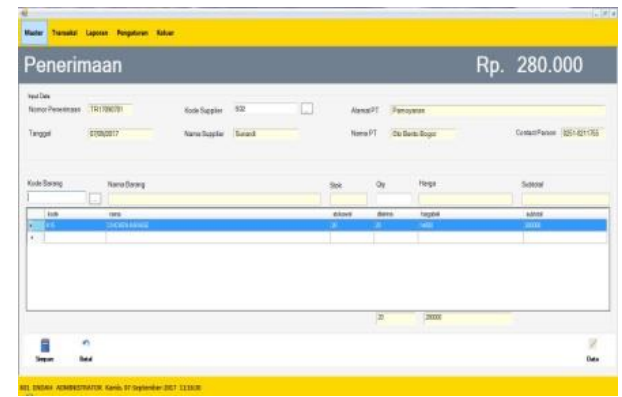

Gambar 7. Form Transaksi Procuk

7. Form Transaksi Pesan Makan

Form transaski pesan makan menampilkan semua data transaksi pesan makan dalam satu tabel di form ini yang telah tersimpan di database dan untuk menginput pesanan pelanggan beserta total bayarnya.

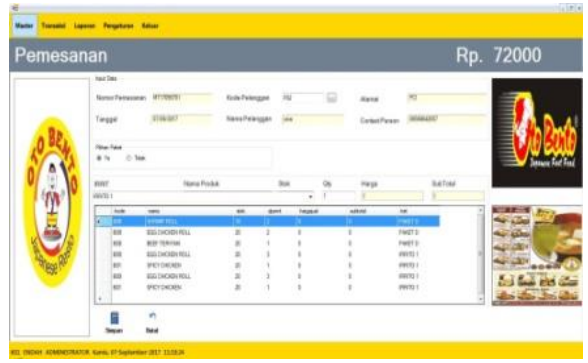

Gambar 8. Form Transaksi Pemesanan

8. Form Laporan Data Pembelian

Form laporan data pembelian menampilkan semua data pembelian yang dapat disajikan per tanggal maupun bulan pembelian bahan baku. 


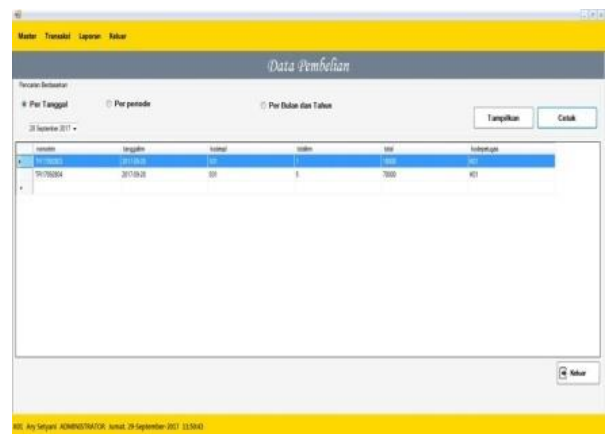

Gambar 9. Form Laporan Pembelian

\section{Form Laporan Data Pemesanan}

Form laporan data pemesanan menampilkan semua data pemesanan yang dapat disajikan per tanggal maupun bulan pemesanan pelanggan.

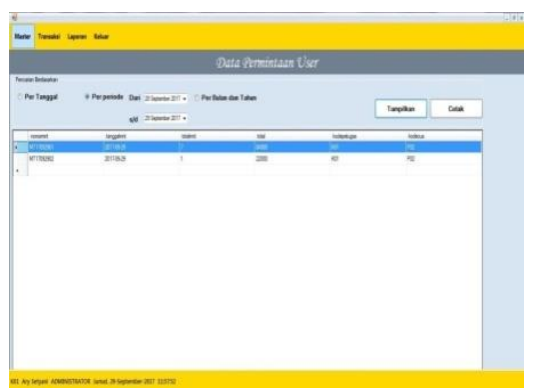

Gambar 10. Form Laporan Pemesanan

\section{IV.Kesimpulan dan Saran}

\section{A. Kesimpulan}

Berdasarkan uraian dan pembahasan yang telah disajikan pada bab-bab sebelumnya, maka penulis menarik kesimpulan dalam pengolahan data inventory pada Oto Bento Cabang Perumnas Cilegon sebagai berikut:

1. Aplikasi inventory dirancang dan dibangun menggunakan metode pemodelan UML (Unified Modelling Language) sebagai gambar fisik aplikasi, dan konsep waterfall sebagai tahapan dalam perancangan aplikasi. Serta menggunakan pemrograman Vb.Net dan SQL Server sebagai databasenya, dengan adanya aplikasi inventory berbasis dekstop ini memudahkan dalam pengecekan jumlah bahan baku yang sesuai dengan kebutuhan perusahaan.

2. Dengan menggunakan aplikasi inventory, maka proses pembelian bahan baku dari supplier dan proses order system makanan dapat disimpan secara terkomputerisasi. Sehingga dalam proses pembuatan laporan akan lebih mudah, cepat dan akurat.

3. Dengan menggunakan aplikasi ini maka proses order system konsumen pada Oto Bento Perumnas Cilegon menjadi lebih cepat, karena jika masih menggunakan cara tulis tangan seperti sebelumnya selain lambat proses order system konsumenpun sering mengalami kesalahan pendataan pesanan

\section{B. Saran}

Ada beberapa saran yang ingin penulis sampaikan di sini yang berhubungan dengan pengoprasian dan pengembangan program aplikasi ini antara lain:

1. Pada penelitian selanjutnya diharapkan aplikasi inventory berrbasis dekstop ini dapat dikembangkan menjadi aplikasi berbasis Android. Agar ketika perkembangan perusahaan semakin besar, maka proses pengembangan sistem akan lebih mudah

1. 2. Untuk pengembangan sistem selanjutnya diharapkan dapat menambah ruang lingkup integrasi sistem lainnya, seperti sistem yang berjalan di bidang keuangan, SDM, dan lain sebagainya.

\section{Daftar Pustaka}

[1] Adnyana, I. M. (2016). "Perancangan Sistem Informasi Akademik STIKES Wira Medika Bali Berbasis Dekstop". Jurnal Sistem dan Informatika , Vol.10, No. 2.

[2] Chandra, M. C., \& Wiradinata, T. (2015). "Rancang Bangun Sistem Informasi Inventory (Studi Kasus UD Sejahtera). JUISI, Vol. 1, No. 2.

[3] Maimunah, Lusyani Sunarya, Nina Larasati. 2012. "Media Company Profile Sebagai Penunjang Informasi dan Promosi". Journal CCIT Vol-5 No.3 - Mei 2012

[4] Rahman, K., Sulistiowati, \& Soebijono, T. (2014). "Rancang Bangun Sistem Informasi

Persediaan Barang Dagangan Pada UD Sarua Subur Cabang Bangkalan". JSIKA, Vol. 3, No. 2.

[5] Safitri, S. T., \& Supriyadi, D. (2015). "Rancang Bangun Sistem Informasi Praktek Kerja Lapangan Berbasis Web dengan Metode Waterfall". Jurnal Infotel, Vol. 7, No. 1.

[6] Sudarsono, N., \& Sukardi. (2015). "Sistem Informasi Inventory Berbasis Web di PT Autotech Indonesia". Eksplora Informatika, Vol. 5, No. 1 [7] Sutabri, Tata. 2012. "Analisis Sistem Informasi”. Yogyakarta: Andi Offset.

[7] Sutarman. 2012. "Buku Pengantar Teknologi Informasi”. Jakarta: Bumi Aksar 